Volume 15, No. 1, Januari 2018

\title{
PERBANDINGAN KADAR EMISI GAS BUANG KARBON MONOKSIDA (CO) PADA KENDARAAN BERMOTOR SISTEM INJEKSI OTOMATIS
}

\author{
Evi Susilawati, Zulfikar Ali As, Munawar Raharja \\ Poltekkes Kemenkes Banjarmasin Jurusan Kesehatan Lingkungan \\ Jl. H. Mistar Cokrokusumo No.1A Banjarbaru Kalimantan Selatan 70714 \\ E-mail: evisusilawati17@gmail.com
}

\begin{abstract}
The Comparison Of Emission Levels Of Carbon Monoxide Exhaust Gas In Automatic Motor Vehicle Injection System. Transportation plays a very big role as a source of air pollution, especially exhaust emissions reach 60-70\%. CO emitted by motor vehicle which exceed the standard be able to cause disturbance and even death. The development of a two-stroke engine vehicle into a four-step engine is a people demand who want a vehicle which is easy and comfortable. Indonesia has many different types of vehicles, but two types of motor vehicles with the YMJET-FI and PGM-FI system are most on the market. Three fuels such as premium, pertalite and pertamax are used by the public. This research was observational analytic, using Posttest Only Design to analyze the CO emission from YMJET-FI and PGM-FI engine with premium fuel, pertalite and pertamax. CO emission was tested at engine speed of 1.900-2.000 rpm and temperature $80^{\circ} \mathrm{C}$. Analysis used Two Way Analysis of Variance statistic test with $\alpha=0,05 \%$. The results showed that YMJET FI using premium emitted CO as 0,23\%, pertalite 0,32\% and pertamax $0,37 \%$. PGM-FI using premium emitted $0,21 \%$, pertalite $0,24 \%$ and pertamax $0,25 \%$. The conclussion is, both of YMJET-FI and PGM-FI, using premium, pertalite and pertamax emitted CO lower than the emission quality standard according to KemenLH 2009 such as of $4,5 \%$.
\end{abstract}

Keywords: Carbon monoxide levels; YMJET-FI and PGM-FI machine; Fuel

\begin{abstract}
Abstrak: Perbandingan Kadar Emisi Gas Buang Karbon Monoksida (CO) Pada Kendaraan Bermotor Sistem Injeksi Otomatis. Transportasi memegang peran sangat besar sebagai sumber polusi udara, khususnya emisi gas buang mencapai 60-70\%. Emisi CO kendaraan bermotor yang melebihi standar dapat menyebabkan gangguan kesehatan bahkan kematian. Pengembangan kendaraan mesin 2 langkah menjadi mesin 4 langkah merupakan tuntutan masyarakat yang menginginkan kendaraan yang mudah dan nyaman. Indonesia memiliki berbagai tipe kendaraan, namun dua tipe kendaraan bermotor dengan sistem injeksi mesin YMJET-FI dan PGM-FI yang paling ramai di pasaran. Dan tiga bahan bakar seperti premium, pertalite dan pertamax yang digunakan oleh masyarakat. Penelitian ini bersifat observasional analitik, dengan menggunakan desain Posttest Only Desain untuk menganalisis hasil akhir kadar emisi CO dari mesin YMJET-FI dan PGM-FI berbahan bakar premium, pertalite dan pertamax. Pengujian dilakukan dengan putaran mesin 1.900-2.000 rpm dan suhu $80^{\circ} \mathrm{C}$. Analisa data menggunakan uji statistic Two Way Analysis of Variance dengan nilai $\alpha 0,05 \%$. Hasil pengujian kadar emisi CO pada mesin YMJET-FI berbahan bakar premium 0,23\%, pertalite 0,32\% dan pertamax 0,37\%. Pada mesin PGM-FI berbahan bakar premium $0,21 \%$, pertalite 0,24\% dan pertamax 0,25\%. Kadar emisi CO pada kedua mesin dan ketiga bahan bakar masih memenuhi baku mutu emisi sebesar 4,5\% menurut KemenLH 2009.
\end{abstract}

Kata kunci: Kadar CO; Mesin YMJET-FI dan PGM-FI; Bahan Bakar

\section{PENDAHULUAN}

Di kota-kota besar, kontribusi gas buang kendaraan bermotor sebagai sumber polusi udara terbesar mencapai 60 -
$70 \%$, sementara kontribusi gas buang dari cerobong asap industri yang hanya berkisar antara $10-15 \%$ dan sisanya berasal dari sumber pembakaran lain, misalnya 
rumah tangga, pembakaran sampah, kebakaran hutan/ladang dan lain-lain[1]. Emisi gas buang pada kendaraan bermotor yang tidak memenuhi standar mempunyai pengaruh negatif bagi manusia, diantaranya CO. Disaat bernafas CO ikut terhirup sampai keparu-paru, bergabung dan terikat dengan hemoglobin $(\mathrm{Hb})$ yang menyebabkan hemoglobin terganggu membawa oksigen keseluruh tubuh. CO yang terhirup pada konsentrasi tinggi dapat menyebabkan kematian[2], maka untuk itu diatur oleh Peraturan Menteri Lingkungan Hidup Negara Republik Indonesia Nomor 04 tahun 2009 tentang ambang batas emisi gas buang kendaraan bermotorbaru dengan ketentuan batas maksimum 4,5\% untuk CO[3].

Pengembangan dan penelitian mengenai mesin 2 langkah menjadi Mesin 4 langkah. Hal ini merupakan tuntutan dari masyarakat yeng mengingikan kendaraan bermotor yang mudah dan nyaman. Mesin 4 langkah terbagi menjadi mesin dengan sistem injeksi dan non injeksi (karburator). Diantara teknologi tersebut pengembangan mesin kendaraan dengan sistem bahan bakar injeksi (Electronic Fuel Injection = EFI), yang secara perlahan-lahan menggeser teknologi sistem bahan bakar konvensional (karburator). Penggantian sistem bahan bakar konvensional ke sistem injeksi dimaksud agar meningkatkan kerja dan tenaga mesin (power), efisiensi bahan bakar, emisi gas buang ramah lingkungan dan akselerasi yang lebih baik jika dibandingkan dengan sistem bahan bakar konvensional, penggunaan mesin dengan sistem bahan bakar injeksi ini mensyaratkan penggunaan bahan bakar tanpa timbal (Bakeri dan Kusairi, 2012)[4].

Di Indonesia perkembangan otomotif dipasaran berbagai tipe cukup banyak, namun dua produsen tipe kendaraan bermotor dengan sistem injeksi mesin YMJET-FI dan PGM-FI yang paling ramai di pasaran. Sistem mesin YMJET-FI adalah suatu sistem bahan bakar dari tangki dipompa oleh pompa bahan bakar ke injektor secara bertekanan, selanjutnya sensor-sensor memberikan inputan kepada engine control unit (ECU) terha- dap kondisi mesin, sehingga engine control unit (ECU) memerintahkan injektor untuk menyemprotkan bahan bakar sesuai kebutuhan mesin[5]. Sedangkan sistem mesin PGM-FI adalah suatu sistem suplai bahan bakar dengan menggunakan teknologi kontrol secara eletronik yang mampu mengatur pasokan bahan bakar dan udara secara optimal yang dibutuhkan mesin pada setiap keadaan. Sistem PGM-FI ini mensuplai bahan bakar ke mesin melalui rangkaian injektor bahan bakar yang di kontrol oleh engine control module (ECM). Tipe sistem mengontrol suplai bahan bakar lebih teliti daripada menggunakan sistem karburator[6].

Berdasarkan latar belakang tersebut maka peneliti tertarik untuk membuktikan dan membandingkan efektifitas mesin kendaraan bermotor sistem injeksi otomatis (YMJET-FI) dan PGM-FI dalam menurunkan kadar emisi CO.

\section{BAHAN DAN CARA PENELITIAN}

Jenis peneitian ini adalah observasional analitik dan menggunakan desain Psttest Only Desain, untuk mengetahui emisi CO yang dihasilkan dari dua jenis mesin (YMJET-FI dan PGM-FI) dengan tiga bahan bakar (premium, pertalite dan pertamax). Populasi dalam penelitian ini adalah semua kadar emisi CO dari mesin YMJEFI dan PGM-FI dengan bahan bakar premium, pertalite dan pertamax. Sampel penelitian adalah kadar emisi CO dari mesin YMJEFI dan PGM-FI dengan bahan bakar premium, pertalite dan pertamax yang ditangkap Gas Analyzer pada periode pengukuran.

Analisa data menggunakan uji statistik Two Way Analysis of Variance dengan tingkat kepercayaan $95 \%$ atau tingkat kemaknaan $\alpha=0,05 \%$ untuk membandingkan rata-rata lebih dari 2 kelompok perlakuan yang berbeda, dengan skala data interval/rasio.

Tahap pengujian: 1) siapkan kendaraan bermotor mesin YMJET-FI dan PGMFI serta bahan bakar premium, pertalite dan pertamax. 2) isi tangki kendaraan dengan bahan bakar (premium/pertalite/pertamax). 3) hidupkan mesin kendaraan $\pm 15-20$ menit, atur putaran mesin 
1.900-2.000 rpm sampai stabil dan suhu mencapai $80^{\circ} \mathrm{C}$. 4) masukkan selang gas analyzer ke knalpot kendaraan (pastikan tidak ada kebocoran/keluarnya emisi selain dijalan utama). 5) hidupkan stopwatch hingga 2 menit setiap kali pengulangan. 6) catat kadar emisi CO yang dihasilkan. 7) lakukan pengulangan sebanyak $5 \mathrm{x}$ setiap mesin kendaraan YMJET-FI dan PGM-FI serta bahan bakar premium, pertalite dan pertamax. 8) akumulasi hasil yang didapatkan lalu rataratakan untuk mendapatkan hasil kadar emisi CO.

\section{HASIL PENELITIAN DAN PEMBAHASAN}

Pengujian kadar emisi gas buang karbon monoksida (CO) dilakukan oleh Dinas Lingkungan Hidup (DLH) kota
Banjarmasin. Kendaraan yang digunakan adalah kendaraan baru yang diproduksi tahun 2017, masih merupakan milik dealer (belum dimiliki perorangan). Pengujian kendaraan bermotor dengan tipe mesin YMJET-FI dilakukan di Banjarmasin sedangkan mesin PGM-FI dilakukan di Martapura, suhu mesin dikondisikan sebesar $80^{\circ} \mathrm{C}$ dan putaran mesin 1.900 $2.000 \mathrm{rpm}$.

Pengukuran suhu lingkungan saat melakukan uji kadar emisi CO pada mesin YMJET-FI di Banjarmasin berkisar antara 31-32 C. Sedangkan pengukuran suhu lingkungan pada saat pengujian kadar emisi mesin PGM-FI dilakukan di Martapura berkisar antara $29-30^{\circ} \mathrm{C}$.

Tabel 1. Kadar Emisi CO Pada Mesin YMJET-FI

\begin{tabular}{ccccc}
\hline Ulangan & \multicolumn{3}{c}{ Kadar CO (\%) pada Kendaraan } & Baku \\
& Premium & Pertalite & Pertamax & Mutu Emisi \\
\hline 1 & 0,06 & 0,09 & 0,16 & \\
2 & 0,16 & 0,36 & 0,25 & \\
3 & 0,23 & 0,38 & 0,45 & $4,5 \%$ \\
4 & 0,31 & 0,38 & 0,46 & \\
5 & 0,39 & 0,39 & 0,52 & \\
Rata-rata & 0,23 & 0,32 & 0,37 & \\
\hline
\end{tabular}

Sumber: Data penelitian 2017

Hasil pengukuran dari mesin YMJET-FI berbahan bakar premium, pertalite maupun pertamax masih memenuhi baku mutu emisi. Hasil pengujian premium lebih baik dari pertalite dan pertalite lebih baik dari pertamax. Rata-rata kadar emisi CO berbahan bakar premium $=0,23 \%$, pertalite $=0,32 \%$ dan pertamax $=0,37 \%$.

Tabel 2. Emisi CO pada Mesin PGM-FI

\begin{tabular}{ccccc}
\hline Ulangan & \multicolumn{3}{c}{ Kadar C0 (\%) pada Kendaraan } & Baku \\
& Premium & Pertalite & Pertamax & Mutu Emisi \\
\hline 1 & 0,07 & 0,11 & 0,15 & \\
2 & 0,09 & 0,22 & 0,21 & \\
3 & 0,21 & 0,27 & 0,26 & $4,5 \%$ \\
4 & 0,32 & 0,29 & 0,30 & \\
5 & 0,34 & 0,33 & 0,32 & \\
Rata-rata & 0,21 & 0,25 & 0,26 & \\
\hline
\end{tabular}

Sumber: Data penelitian 2017

Hasil pengukuran dari mesin PGMFI berbahan bakar premium, pertalite dan pertamax masih memenuhi baku mutu emisi. Hasil pengujian premium lebih baik dari pertalite dan pertalite lebih baik dari pertamax. Rata-rata kadar emisi CO berbahan bakar premium $0,21 \%$, pertalite $0,25 \%$ dan pertamax $0,26 \%$. 
Tabel 3. Hasil Uji Two Way Analisys of Variance

\begin{tabular}{lcccrc}
\hline Source & Type III Sum of Squares & Df & Mean Square & \multicolumn{1}{c}{ F } & \multicolumn{1}{l}{ Sig. } \\
\hline Jenis_mesin & .040 & 1 & .040 & 2.859 & .104 \\
Jenis_BBM & .043 & 2 & .021 & 1.521 & .239 \\
Jenis_mesin*Jenis_BBM & .012 & 2 & .006 & .409 & .669 \\
\hline
\end{tabular}

Sumber: Data penelitian 2017

Nilai p (signifikansi) dari variabel jenis mesin, jenis BBM dan Jenis mesin*jenis BBM berada di atas nilai $\alpha$ $(0,05 \%)$, artinya secara statistik tidak ada perbedaan kadar emisi CO pada mesin YMJET-FI dan PGM-FI pada tingkat kepercayaan 95\%.

\section{PEMBAHASAN}

Pengujian kadar emisi CO dilakukan hari dan tempat yang berbeda sehingga suhu lingkungan yang diukur berbeda namun, dari perbedaan suhu lingkungan tersebut tidak berpengaruh terhadap kadar emisi CO yang dihasilkan disebabkan pengujian dilakukan dengan memasukkan selang gas analyzer kedalam knalpot kendaraan. Pada setiap pengulangan, semakin sering dilakukan pengulangan semakin tinggi kadar emisi CO yang dihasilkan, hal ini dapat disebabkan adanya efek residual yang tersisa didalam mesin pembakaran kendaraan bermotor, namun efek residual kadar emisi CO akan hilang ketika mencapai titik jenuh.

Putaran mesin dan suhu yang rendah kadar emisi CO dengan bahan bakar premium lebih baik dari pada pertalite dan pertamax. Hal ini disebabkan premium mudah terbakar secara sempurna didalam mesin dan sifat premium yang mudah teurai dan memiliki titik didih yang rendah, sehingga kadar emisi CO yang dihasilkan premium lebih rendah dari pertalite dan pertamax. Pada saat suhu dan putaran mesin tinggi pertalite dan pertamax akan cocok dengan putaran dan suhu tinggi karena memiliki nilai oktan yang tinggi, sehingga dapat menerima tekanan pada mesin berkompresi tinggi agar tidak terjadi ledakan secara spontan sebelum percikan api dari busi dan dapat bekerja dengan optimal.

Menurut Aziz (2015) konsentrasi emisi gas buang karbon monoksida (CO) cenderung lebih tinggi pada putaran mesin rendah antara 1.500-2.000 rpm dan pada putaran mesin tinggi $2.500-$ $3.500 \mathrm{rpm}$ cenderung rendah. Hal ini diakibatkan pada putaran rendah throttle position sensor pada throttle body memberi feedback pada ECU jika throttle terbuka sedikit menandakan mesin sedang melakukan akselerasi dari putaran mesin $1.500 \mathrm{rpm}$ sehingga bahan bakar yang disemprotkan akan lebih banyak[7]. Gunandi (2010) dalam Bakeri (2012) menyatakan bahwa gas karbon monoksida (CO) adalah gas yang relatif tidak stabil dan cenderung bereaksi dengan unsur lain. $\mathrm{CO}$ dapat diubah dengan mudah menjadi karbon dioksida $\left(\mathrm{CO}_{2}\right)$ dengan bantuan sedikit oksigen dan panas. Saat mesin bekerja dengan bahan bakar udara $(A F R)$ yang tepat, emisi $\mathrm{CO}$ pada ujung knalpot berkisaran 0,5\% sampai $1 \%$ dengan putaran mesin 3.000 rpm untuk mesin yang dilengkapi dengan sistem injeksi[8]. Kadar emisi CO tinggi pada rpm rendah ini dapat disebabkan karena rantai atom $\mathrm{C}$ dan $\mathrm{H}$ dalam premium lebih kecil dibanding pertalite dan pertamax. Dengan kecilnya rantai atom C dalam premium maka potensi untuk terbentuknya gas $\mathrm{CO}$ setelah pembakaran akan semakin kecil. Selain itu, dapat dipengaruhi oleh lambda pada putaran idle[9].

Kadar emisi CO yang dihasilkan menunjukan mesin PGM-FI sedikit lebih rendah dibandingkan mesin YMJET-FI ini disebabkan ruang kompresi PGM-FI lebih besar dibandingkan dengan ruang mesin YMJET-FI sehingga suhu dan tekanan mesin pada ruang bakar lebih tinggi. Dan power yang dihasilkan lebih besar serta lebih irit bahan bakar yang digunakan [10].

Menurut Ganesan (2004) dalam Wisesa (2015) salah satu proses pembakaran dapat dipengaruhi oleh 
perbandingan kompresi "The compression ratio in most SI engine is limited by knock and the use economically feasible antiknock quality fuel". Pernyataan tersebut menjelaskan bahwa perbandingan kompresi pada SI engine dibatasi karena akan menyebabkan knock, sehingga menggunakan kualitas bahan bakar yang ekonomis serta memiliki sifat antiknock. Pengaruh peningkatan perbandingan kompresi menjadi tekanan dan temperatur dalam silinder juga mengalami peningkatan, sehingga mempengaruhi konsentrasi CO dalam proses pembakaran dan menghasilkan banyak kandungan CO yang cukup signifikan, walaupun oksigen dalam keadaan cukup. Hal ini sebabkan adanya disosiasi molukel $\mathrm{CO} 2$ menjadi $\mathrm{CO}$ dan $\mathrm{O}_{2}$. Variabel utama yang mempengaruhi Unburned Hydrocarbon (UHC) dalam SI engine adalah perbandingan campuran, perbandingan kompresi, kecepatan mesin dan waktu pengapian. Kemudian perbandingan kompresi yang tinggi dapat meningkatkan kandungan HC, karena dengan ruang bakar yang lebih kecil akan meningkatkan tekanan lebih besar dari total volume mesin [11].

\section{KESIMPULAN DAN SARAN}

Pada kendaraan bermotor sistem injeksi otomatis mesin YMJET-FI kadar emisi CO yang dihasilkan berbahan bakar premium adalah $0,23 \%$, pertalite $0,32 \%$ dan pertamax $0,37 \%$. Sedangkan mesin PGM-FI berbahan bakar premium adalah $0,21 \%$, pertalite $0,24 \%$ dan pertamax 0,25 $\%$. Perbedaan kadar emisi CO pada kendaraan bermotor injeksi otomatis mesin YMJET-FI dan PGM-FI berbahan bakar premium, pertalite dan pertamax tidak ada perbedaan yang bermakna secara statistik $p>\alpha(0,05)$. Namun secara nominal memiliki perbedaan kadar emisi CO dengan mesin PGM-FI memiliki kadar emisi CO lebih rendah dibanding mesin YMJET-FI, dengan selisih angka premium $0,02 \%$, pertalite $0,08 \%$ dan pertamax $0,11 \%$.

Hasil penelitian menunjukan bahwa penggunaan mesin YMJET-FI dan PGM-FI berbahan bakar premium, pertalite dan pertamax, kadar emisi CO yang dihasilkan tidak melebihi standar baku mutu emisi sehingga dapat digunakan untuk kendaraan sistem injeksi otomatis. Serta perlu dilakukan penelitian lanjutan dengan variasi putaran mesin $(2.500,3.000$ dan 3.500) karena pada putaran mesin rendah (1.900-2.000) sangat berpengaruh terhadap jumlah kadar emisi CO yang dikeluarkan.

\section{KEPUSTAKAAN}

1. Arifin, Z, dan Sukonco. 2009. Pengendalian Polusi Kendaraan. Alfabeta. Bandung.

2. Ryadi, Slamat. 1982. Pencemaran Udara. Usaha Nasional. Surabaya.

3. Badan Lingkungan Hidup. 2016. Uji Kualitas Udara Emisi Gas Buang Kendaraan Bermotor. Sidoarjo. http:// blh.sidoarjokab.go.id/detailberita238-sda-tps-lb3.html. Diakses pada tanggal $01 / 02 / 2017$ pukul 15.30 WITA.

4. Bakeri, Mustafa, Syarief, Akhmad, Kusairi, Ach, 2012. Analisa Gas Buang Mesin Berteknologi Efi Dengan Bahan Bakar Premium. Jurnal Info Teknik, Volume 13 No. 1. Jurusan Teknik Mesin. Universitas Lambung Mangkurat. Banjarbaru. http://ppjp. unlam. ac.id/journal/index.php/infoteknik/a rticle/viewFile/1819/1591. Diakses pada tanggal 01/02/2017.

5. Saifudin, Mohammad, 2013. Sistem Bahan Bakar Pada Yamaha Mio J YMJET-FI. Skripsi Jurusan Teknik Mesin Fakultas Teknik. Universitas Negeri Semarang. Semarang.

6. Pamungkas, Danny Pramudyan, 2013. Troubleshooting Sistem Pengisian Honda Vario Techno 125 PGM-FI. Tugas Akhir JurusanTeknik Mesin Fakultas Teknik. Universitas Negeri Semarang. Semarang.

7. Aziz, Panji Rohman. 2015. Pengaruh Pengaturan CO terhadap Lambda dan Hasil Uji Emisi Sepeda Motor Bermesin EFI. Skripsi. Fakultas Teknik Mesin. Universitas Negeri Semarang. 
8. Bakeri, Mustafa, Syarief, Akhmad, Kusairi, Ach, 2012. Analisa Gas Buang Mesin Berteknologi Efi Dengan Bahan Bakar Premium. Jurnal Info Teknik, Volume 13 No. 1. Jurusan Teknik Mesin. Universitas Lambung Mangkurat. Banjarbaru. http://ppjp. unlam. ac.id/journal/index.php/infoteknik/a rticle/viewFile/1819/1591. Diakses pada tanggal 01/02/2017.

9. Siregar, 2009. Performansi MesinNon Stationer (Mobiel) berteknologi VVT-i. Sumatra Utara. https:// repository.usu.ac.id/bitstream. Diakses pada 03 Februari 2017.

10. Ningrat, A.A Wira Kresna, Kusuma, I.G.B Wijaya, Adnyana, I Wayan
Bandem, 2016. Pengaruh Penggunaan Bahan Bakar Pertalite Terhadap Akselerasi dan Emisi Gas Buang Pada Sepeda Motor Bertransmisi Otomatis. Skripsi. Universitas Udayana. Bali.

11. Wisesa, Budi Utomo, 2015. Pengaruh Peningkatan Prebandingan Kompresi Terhadap Emisi Gas Buang Kendaraan Sepeda Motor Honda Blade 110 CC. www.academia.edu/ 20448290/Pengaruh_Peningkatan_Pr ebandingan_Kompresi_Terhadap_Emi si_Gas_Buang_Kendaraan_Sepeda_Mo tor_Honda_Blade_110_Cc. Diakses pada 17 Juli 2017 pukul 08.00 WITA. 